\title{
CANTA, UNA VISIÓN DE DESTINO TURÍSTICO SOSTENIBLE
}

\author{
Antonieta Hamann Pastorino
}

\section{RESUMEN}

Se describen las potencialidades de Canta para su desarrollo como un destino turístico sostenible. La presencia de diferentes pisos ecológicos le da a esta provincia una variedad de microclimas y zonas de vida a lo largo del valle del río Chillón. De otro lado, sus monumentos arqueológicos, sus fiestas patronales, sus costumbres ancestrales y su cercanía a Lima, la capital del Perú, constituyen factores propicios para el desarrollo de diversas modalidades de turismo. Sin embargo, se requiere contar con la infraestructura adecuada para que el visitante la convierta en un destino preferente.

El tipo de estudio utilizado fue la investigación exploratoria. Se realizaron cuatro entrevistas en profundidad a profesionales canteños que han migrado, pero que mantienen su identificación con su tierra natal. Del estudio efectuado se concluye la importancia de optimizar los atractivos turísticos e implementar la infraestructura necesaria.

Palabras clave: atractivos turísticos, turismo cultural, turismo de aventura, turismo de naturaleza, turismo gastronómico, infraestructura.

\section{INTRODUCCIÓN}

El turismo es un factor de desarrollo para los países, generador de ingresos y de empleo. Su importancia radica en ser la industria con más alto crecimiento mundial y una de las mayores fuentes de puestos de trabajo.

El Perú es un país privilegiado en escenarios naturales, en arqueología y en gastronomía, por nombrar solo algunos ámbitos, lo que hace que la actividad turística desempeñe un papel determinante en la estrategia de crecimiento del país a mediano y largo plazo.

Otro factor por considerar es la gran cantidad de destinos no tradicionales o alternativos con los que se cuenta, los que tienen que adecuarse a las tendencias internacionales para ofrecer no solo estándares de calidad competitivos, sino para que puedan conciliar su crecimiento con un desarrollo sostenible en tiempos y recursos

La provincia de Canta, cuya capital está ubicada a 100 kilómetros al noreste de la ciudad de Lima, está plena de recuerdos y leyendas, con innumerables manifestaciones folclóricas como las danzas de los abuelitos, los viejitos, los chunchitos, los negritos, entre otras; así como también las fiestas del santo patrón o patrona que sirven de reencuentro para quienes nacieron en sus diversas circunscripciones.

Por otra parte, ofrece una variedad de atractivos arqueológicos distribuidos en sus distritos, entre los que destacan los petroglifos de Checta, el complejo de Cantamarca, los restos de Huischo, Tauripunko, 
Cushpa, Pumakoto y Sinchipampa, para mencionar solo algunos de ellos. Cabe recordar que Canta ocupa cinco pisos ecológicos: yunga, quechua, suni, puna y janca, que influyen en su variedad de climas y en la existencia de diversas especies de flora y fauna que habitan dentro de sus límites; por ejemplo, las puyas de Raimondi. Asimismo, son apreciables sus cataratas, sus lagunas y la cordillera de la Viuda.

El turismo en Canta se produce, principalmente, los fines de semana y en los meses de julio y agosto que coinciden con las vacaciones escolares, fiestas patrias y fiestas patronales. La visitan tanto el originario del lugar que vive actualmente en Lima, conserva sus tradiciones, mantiene la propiedad patrimonial de su familia y regresa, primordialmente, para la celebración de sus fiestas patronales; como el turista recreacional procedente de Lima, principalmente de Lima Norte, atraído por el paisaje natural, el descanso y la cercanía a la ciudad.

Sin embargo, la provincia de Canta no ha desarrollado. Existe una gran deficiencia de infraestructura turística, como la falta de mantenimiento de las vías de acceso, servicios de hospedaje y de gastronomía básicos y de poca calidad, además de la ausencia de facilitación turística.

En este contexto, se reconoce la necesidad de optimizar los atractivos turísticos y de un trabajo conjunto entre el sector público y el privado para implementar la infraestructura requerida que ofrezca una estadía competitiva al visitante.

\section{MARCO TEÓRICO}

En este apartado se van a desarrollar conceptos tales como el turismo, sus componentes y el producto turístico para fundamentar que Canta es una provincia con potencial para ser un destino turístico sostenible.

\subsection{El turismo}

Meyer (2002) plantea, por un lado, que el turismo se construye y prospera gracias a la existencia de atractivos naturales, culturales y de otro tipo, a condición de que estos se encuentren en buen estado de conservación, de modo que el turismo pueda utilizarlos pero no agotarlos. Por otro lado menciona que varias zonas del mundo se han caracterizado por seguir una estrategia de crecimiento ilimitado de la oferta y de la demanda, lo que ha traído consigo un deterioro, a veces irreversible, del medio ambiente natural, histórico y cultural. Por ello enfatiza que solo siguiendo una estrategia de desarrollo sostenible se puede garantizar que los recursos que utiliza el turismo mantengan sus cualidades originales.

Morán (2001) coincide con Meyer en que turismo, desarrollo regional y protección del medio ambiente podrían ir a la par si existe planificación y control adecuado de los recursos. Del mismo modo, Torres (2005) expresa que el turismo, además de ser un fenómeno social y económico, presenta una vertiente geográfica que es la que suele servir de sustento físico a los recursos consumidos, tanto durante el itinerario como en el período de estancia; y que el turismo interactúa con tres variables: el medio físico biótico y abiótico, la realidad sociocultural del destino y sus circunstancias socioeconómicas.

La noción de equilibrio entre los objetivos económicos, sociales y ambientales constituye el argumento central del modelo conceptual de turismo sostenible planteado por C. Hall (Ascensión, 2005), basado en tres elementos esenciales: el lugar, la comunidad local y el visitante. Asimismo, se menciona que la sostenibilidad no puede identificarse como un estado ideal, sino más bien como un proceso de cambio cualitativo, postulado de la Organización Mundial del Turismo (OMT) que liga el concepto de sostenibilidad a la calidad, la continuidad y el equilibrio. Es así que la OMT (Pérez, 2004) plantea el turismo sostenible como un modelo de desarrollo económico diseñado para mejorar la calidad de vida de la población local, proveer mayor calidad a la experiencia del visitante, preservar el medio ambiente, conseguir mayores niveles de rentabilidad económica para los residentes locales y asegurar la obtención de beneficios por parte de los empresarios turísticos.

En este sentido, Meyer (2002) menciona que el turismo orientado a la naturaleza representa un eficaz instrumento de desarrollo sostenible que no 
requiere de grandes inversiones en infraestructura y equipamiento, o de la importación de insumos, o de la utilización de tecnología sofisticada, sino más bien de poseer atractivos naturales y culturales para explotar, de tener posibilidades de realizar actividades turísticas y de contar con personas calificadas para brindar los servicios necesarios. El turismo, añade, no solo contribuye al desarrollo social y económico de los países, sino que colabora a la conservación y revaloración del medio ambiente y de los recursos culturales y naturales.

Dentro de esta misma perspectiva, Pantano (2002) enfatiza que las preferencias de los turistas seorientan a las actividades vinculadas con la naturaleza y que el turismo es una actividad económica, lo que significa que es operado y comercializado por empresas, por lo que la sostenibilidad del turismo depende de la rentabilidad de estas. Esto lleva a que el turismo funcione de manera eficiente; es decir, a la utilización óptima de los recursos físicos, humanos, naturales, así como a su cuidado, no a su explotación. En este punto, conviene referirse a los actores que están involucrados quienes, según Pantano (2002), serían los siguientes:

- El poseedor, vale decir la comunidad dueña del recurso, responsable de conservarlo para las generaciones futuras y para la humanidad, y receptora de los beneficios generados por su utilización.

- El custodio, representado por la institución y los funcionarios encargados de la conservación y preservación del recurso (municipio, administración de parques).

- El operador, que es la empresa que hace posible el aprovechamiento y disfrute del recurso, la que comercializa, la que trae a los turistas y obtiene beneficios de ello.

- Los turistas que viven la experiencia y posibilitan tanto el negocio para las empresas como los beneficios para la comunidad.

Para alcanzar la sostenibilidad-siempre siguiendo a Pantano-, lo importante es conseguir que estos actores actúen de modo coordinado y que cada uno cumpla su papel responsablemente frente a los demás.
Por su parte, Ascensión (2005) señala que para lograr un turismo sostenible se requiere de una adecuada planificación de uso territorial regional, local, comunal y zonal, así como de áreas naturales en estado de permanente conservación. Menciona asimismo que deben participar las comunidades, el Estado, las empresas operadoras de tours y que la actividad ha de ser controlada y guiada a través de modelos de capacidad de carga y monitoreos periódicos. Guerra (2002) coincide en que la planificación constituye un conjunto de métodos y medidas que permite a las sociedades avanzar con un mayor grado de certeza y éxito en su desarrollo socioeconómico y ambiental para establecer un equilibrio entre cultura y naturaleza.

En el mismo sentido, Barretto (2007) comenta que el turismo incluye, de un lado, la planificación y, del otro, la comercialización; donde la planificación debe ser responsabilidad de organismos públicos gubernamentales que contemplen tanto los intereses de los empresarios de turismo como los de las comunidades receptoras, así como el bienestar de los propios turistas. Asimismo señala que en gran parte de los países del mundo y en particular en América Latina este planeamiento es inexistente o parcialmente inexistente. Indica que la oferta turística es planificada por los empresarios, buscando maximizar sus ingresos sin tomar en cuenta a la población y a la naturaleza. Por otro lado menciona que la comercialización de estos productos obedece a las técnicas comunes de marketing. Es así que el turismo es un producto que se elabora con las materias primas de la naturaleza (recursos naturales), sumados a los equipamientos para prestar servicios de recreación, alimentación y hospedaje, a los que se llega a través del transporte.

\subsection{Componentes del turismo}

Los componentes del turismo son, de un lado, los turistas que constituyen la demanda y, de otro, los creadores de atracciones turísticas y la atracción en sí misma que conforman la oferta, juntamente con los prestadores de servicios. Barretto (2007) agrega que el turismo es un fenómeno que crece y se expande en forma bastante incontrolable e imprevisible a través del tiempo y del espacio. En cada momento y lugar en los que se produce el fenómeno turístico se origina una serie de relaciones 
que siempre son, en algún grado, diferentes y nunca totalmente pronosticables. Del mismo modo señala que las situaciones de turismo no se reproducen ni siquiera en el turismo llamado de masas. Finalmente indica que el turismo presupone la existencia de infraestructura (hoteles, restaurantes, carreteras, aeropuertos) y la disponibilidad de atractivos. De tal manera que turistas, atracciones, recursos y servicios son interdependientes pero autónomos.

\subsection{Producto turístico}

Consiste en la integración de los atractivos turísticos, el equipamiento turístico e infraestructura, los bienes y servicios de apoyo, la gestión que desarrollan los actores involucrados en la actividad turística, la imagen del destino y el precio (Leiva, 1997). Al respecto, Bazán y otros (2007) mencionan que un producto turístico es la combinación de elementos tangibles e intangibles que ofrecen una serie de beneficios al turista, como respuesta a sus motivaciones y expectativas: atractivos turísticos, empresas de servicios turísticos, infraestructura y superestructura, entre otros.

\section{a) Atractivos turísticos}

Según Couillaud (2006), los recursos que atraen al turista hacia un determinado lugar y no a otro se pueden reunir en tres grandes grupos: los elementos naturales que comprenden los paisajes, playas, montañas, nevados, fauna, flora, entre otros; los elementos físicos referidos a las condiciones climáticas; y los elementos culturales que incluyen el arte, la arqueología, el folclore, la gastronomía y la religión, entre otros. Couillaud describe en detalle estos recursos turísticos:

- Actividades culturales: Se relacionan con las manifestaciones culturales, arqueológicas o artísticas que ayudan al enriquecimiento intelectual. Los destinos privilegiados son los núcleos históricos, vestigios arqueológicos, museos, ruinas, monumentos, folclore, entre otros. El patrimonio cultural es muy amplio y registra una larga evolución histórica y constituye la esencia misma de las identidades nacionales y locales.

- Actividades deportivas y de aventura: La carac- terística propia y más relevante en esta modalidad de turismo es que el viajero toma parte activa en el viaje, realizando deportes náuticos, canotaje, caminatas, caza, pesca, entre otras.

- Actividades recreativas y de diversión: Son las actividades de carácter lúdico, los parques de atracciones, las piscinas, los clubes, etc.

- De naturaleza o ecoturismo: Modalidad turística ambientalmente responsable, que consiste en viajar o visitar áreas naturales con el fin de disfrutar, apreciar y estudiar los atractivos naturales (paisaje, flora y fauna silvestre), conservando el medio ambiente.

- De salud: Ofrece gran cantidad de tratamientos para distintas dolencias, que se pueden realizar de forma natural o no, dependiendo de técnicas y especializaciones médicas que haya desarrollado el lugar.

- Rural: Asociado a la creciente sensibilidad medioambiental. Comprende desde el turismo relacionado a la agricultura hasta aquel enfocado en la naturaleza.

- Vivencial: Consiste en que las familias, dedicadas principalmente a tareas agropecuarias, deportivas y de pesca artesanal abran sus casas para alojar al visitante y compartan con ellos sus actividades diarias.

- Religioso, peregrinación: Atrae personas que profesan determinada fe y que se muestran atraídas por conocer monumentos, templos o sitios que simbolizan un credo, un personaje religioso, entre otros.

- Místico y esotérico: Esta forma de turismo utiliza los conocimientos ancestrales e interesa a aquellos viajeros ansiosos por descubrir las milenarias tradiciones espirituales y los grandes enigmas que envuelven a ciertas culturas. EI turismo esotérico se centra principalmente en la explotación de ciertos lugares que la gente relaciona con lo mágico y místico.

Otras modalidades podrían ser el turismo educativo, en el cual los docentes llevan de visita a los alumnos a granjas para ver distintas especies animales e 
instruirlos sobre los sistemas productivos; el turismo gastronómico, basado en las bondades culinarias y productos del lugar; el turismo étnico, visitando comunidades de pueblos originarios; el turismo de eventos para realizar matrimonios, cumpleaños y reuniones empresariales.

\section{b) Empresas de servicios turísticos}

Conforman los servicios brindados al turista como el transporte, hotelería, restauración, diversiones y organización de viajes, entre otros. Estos servicios tienen la particularidad de ser intangibles, es decir que no pueden ser experimentados, sentidos, probados u olidos antes de ser experimentados, por lo que resulta imposible saber con certeza si van a ser satisfactorios para el cliente antes de su prestación (Bazán y otros, 2007). Los consumidores buscan la calidad del servicio, por lo que el proveedor debe lograr que esta sea lo más tangible posible a través del local, del personal, del equipamiento y del precio, por lo que la interacción entre el proveedor y el cliente será un aspecto clave en el resultado final.

\section{c) Infraestructura}

Compuesta por los servicios básicos, vías de acceso y obras públicas que permiten la llegada del turista a su destino y su desplazamiento interno (Bazán y otros, 2007). Toca a los gobiernos regionales (Ascención, 2005) promover y ejecutar las inversiones públicas de ámbito local en proyectos de infraestructura vial, energética, de comunicaciones, de servicios básicos con estrategias de sostenibilidad. En este sentido, Acerenza (2008) menciona que el desarrollo del turismo requiere invertir en infraestructura básica y red vial, en la construcción de sistemas de saneamiento, alcantarillado y agua potable, en el acondicionamiento de las facilidades turísticas, la prestación de servicios públicos, la información y asistencia a los turistas, entre otros.

\section{d) Superestructura}

Implica el marco legal e institucional que regula y fomenta la participación de las organizaciones públicas y privadas, tanto nacionales como internacionales, relacionadas con la actividad turística (Bazán y otros, 2007).

\subsection{Demanda turística}

Fernández de Tejada e Iniesta (1999) señalan que se ha desarrollado una mayor concienciación de la sociedad en temas de la naturaleza, lo que ha generado una demanda por este tipo de turismo. Mencionan además que la naturaleza ofrece aspectos de carácter psicológico, moral y religioso, revelándose como el entorno idóneo para actividades educativas y científicas, y que las personas tienen la necesidad de superarse y de admitir retos, lo que ha dado origen a actividades de turismo deportivo o de aventura.

Por otro lado, Barretto (2007) señala que muchos turistas buscan el reencuentro con el pasado, con sus raíces, mantener algún tipo de identidad, manifestada en la pertenencia a determinados grupos: religiosos, políticos, etc. Las personas pasan a sentir que la identidad es una construcción social.

\section{METODOLOGÍA}

El tipo de estudio utilizado fue la investigación exploratoria. Hernández y otros (2003: 100) afirman que el objetivo de este tipo de trabajos es "examinar un tema o problema de investigación poco estudiado, del cual se tienen muchas dudas o no se ha abordado antes". Los autores comentan también que tales estudios son usados para indagar temas o áreas desde nuevas perspectivas, con un enfoque cualitativo.

Entre enero y febrero del 2011 se realizaron cuatro entrevistas en profundidad a profesionales canteños que han migrado pero continúan identificados con su provincia: Mílciades Hidalgo $(\mathrm{MH})$, Bernardino Ramírez (BR), Guillermo Vento (GV) y Diego Vicuña (DV).

A los entrevistados se les hizo preguntas relacionadas a los atractivos turísticos que consideran de interés para el visitante, a la oferta turística y a la influencia de esta actividad para el desarrollo de Canta. Las preguntas se agruparon en las siguientes categorías: tipo de turismo, servicios turísticos, infraestructura e importancia del turismo. 


\section{TIPO DE TURISMO}

\begin{tabular}{|c|c|}
\hline TIPO DE TURISMO & ENTREVISTADO \\
\hline De naturaleza o ecoturismo & $\begin{array}{l}\text { BR: Los paisajes, la cordillera de la Viuda es un macizo interesante. } \\
\text { Tiene cochas muy hermosas, lagunas, además de una serie de } \\
\text { cascadas muy bonitas. Se pueden ver entre Huacos y Huaros, en } \\
\text { Tingo; entre Lachaqui y Carhua, en Huamantanga; entre Marco y } \\
\text { Quipán. Hay que poner en valor esas caídas de agua, las lagunas, } \\
\text { los paisajes. } \\
\text { MH: Los pisos ecológicos. } \\
\text { GV: El clima es puro y fresco. El relieve es casi una gradería, un } \\
\text { anfiteatro gigante. Los andenes de las yungas. La cantuta, la puya } \\
\text { de Raimondi. Una vista panorámica. La gente va porque le gusta } \\
\text { la flora y fauna. Poseemos seis pisos ecológicos. Los pueblos } \\
\text { tienen el río, la planicie que exhiben y sobre todo los paisajes tan } \\
\text { bonitos y la tranquilidad. } \\
\text { DV: El valle de Chillón. El cañoncito de Pacrón. El recorrido del } \\
\text { río con paisajes extraordinarios. También las lomitas en Goyo. Si } \\
\text { hubiera miradores la gente acudiría. Hay para hacer como quince } \\
\text { proyectos de miradores. El parque de Obrajillo. El paisaje abierto. } \\
\text { En Canta cada doscientos metros cambian los microclimas. La } \\
\text { flora en todas las zonas, sobre todo en la chala. Las puyas de } \\
\text { Raimondi, no hay que ir hasta Áncash para verlas. }\end{array}$ \\
\hline Cultural & $\begin{array}{l}\text { BR: Las iglesias coloniales, por ejemplo en Arahuay, en Buenaventura, } \\
\text { en Huamantanga. } \\
\text { MH: Poner en valor Santa Rosa de Quives o el pueblito de Santa } \\
\text { Rosa de Acochaca. Los petroglifos de Checta. Las ruinas de } \\
\text { Carhua, según los libros hay una momia de una madre que está } \\
\text { con su feto, un ícono. La cultura de los huanchos. } \\
\text { GV: Tenemos caminos preincaicos e incaicos. Las ruinas de } \\
\text { Cantamarca, las de Huanchos, las de Tauripunco. Los petroglifos } \\
\text { de Checta. El pueblo de Acochaca. El campo de batalla de } \\
\text { Quillapata. } \\
\text { DV: Tenemos tres o cuatro motivos en cuestión de historia: } \\
\text { Quillapata, Sángrar, Huamantanga. Las ruinas de Cantamarca. } \\
\text { Aynas y Huishco, encima de Huaros. En San Miguel hay un lugar } \\
\text { que se llama Pueblo Viejo donde hay unas cabezas clavas como } \\
\text { las de Chavín, aunque un poco maltratadas. En varios lugares } \\
\text { hay "pueblos viejos", los Ilaman así, son sus ruinas. En Carhua } \\
\text { también se han encontrado momias como "Juanita" y ahí hay un } \\
\text { museo de sitio muy sencillito. Los petroglifos de Checta. }\end{array}$ \\
\hline
\end{tabular}




\begin{tabular}{|c|c|}
\hline Gastronómico & $\begin{array}{l}\text { BR: Hay comidas regionales como, por ejemplo, la pachamanca, } \\
\text { la carapulcra, el patache, la sopa de habas. También, cuyes y } \\
\text { conejos a la brasa serían buenos platos. La trucha de Cullihuay. } \\
\text { GV: La gastronomía tiene que desarrollarse haciendo hincapié } \\
\text { en las comidas típicas como, por ejemplo, el puchero, la propia } \\
\text { pachamanca, el picante de cuyes y también la trucha que ahora } \\
\text { está en boga. }\end{array}$ \\
\hline Recreativos y diversión & $\begin{array}{l}\text { BR: Construir recreos en muchas zonas. } \\
\text { MH: La gente va a hacer recreación, a pasearse, pero no se tiene } \\
\text { infraestructura que atienda esa necesidad. }\end{array}$ \\
\hline Rural & $\begin{array}{l}\text { GV: La zona frutícola yunga en la comunidad de Pampacocha. } \\
\text { Los maizales de Yaso, Pampacocha y Acochaca. }\end{array}$ \\
\hline Vivencial & $\begin{array}{l}\text { BR: Se está haciendo turismo vivencial en los pueblos de Collo, } \\
\text { Puruchuco y Marco. } \\
\text { DV: Hacer el turismo vivencial. Ahora hay poquísimos lugares } \\
\text { donde se crían vacas y sacan leche. Antes era extraordinario ver } \\
\text { toda una Canta florecida y con vacas por aquí y por allá. }\end{array}$ \\
\hline Fiestas religiosas, costumbristas & $\begin{array}{l}\text { BR: La fiesta del toro afuera. La del Señor de los Milagros. Hay que } \\
\text { fortalecer las fiestas. } \\
\text { MH: Las fiestas patronales tienen una significación enorme para } \\
\text { todos, rememorar vivencias. } \\
\text { GV: Son muy atractivas para los turistas. En septiembre, en la } \\
\text { fiesta del Chaperito, se pueden ver bailes muy bonitos como los } \\
\text { chunchitos, los viejitos, los negritos, que son unas escuelas muy } \\
\text { singulares que hay ahí. } \\
\text { DV: El toro afuera, que tiene una cantidad enorme de seguidores. } \\
\text { Canta tiene tres imágenes sagradas: la Virgen de la Cueva Santa en } \\
\text { Pariamarca, el Chaperito y el Señor de Huamantanga. }\end{array}$ \\
\hline Deportivo y aventura & $\begin{array}{l}\text { BR: Tener deportes, por ejemplo parapentes, motociclistas. } \\
\text { GV: El relieve de Canta permite el trekking, la bicicleteada, el } \\
\text { deporte y la práctica de andinismo. }\end{array}$ \\
\hline Educativo & $\begin{array}{l}\text { MH: Los aportes arqueológicos interesan a los universitarios, a } \\
\text { los profesionales y a los colegios. Los centros educativos van a } \\
\text { Canta con cierta frecuencia. } \\
\text { DV: Llevar a los alumnos de colegios y de universidades. }\end{array}$ \\
\hline
\end{tabular}




\section{SERVICIOS TURÍSTICOS}

\begin{tabular}{|l|l|}
\hline SERVICIOS TURÍSTICOS & ENTREVISTADO \\
\hline Alojamiento (hotelería) & $\begin{array}{l}\text { BR: En Canta hay tres hoteles que dan buena atención. También se puede } \\
\text { restaurar las casonas, hacer hospedajes como en el Cuzco. Hay que } \\
\text { trabajar con los propietarios y con el gobierno local y regional. } \\
\text { GV: No hay suficiente planta turística. Hay un déficit. Incrementar las } \\
\text { casas-hospedajes. En Canta el } 60 \% \text { de casas está desocupado. } \\
\text { DV: En Canta hay un par de buenos hoteles. Los demás son de mediocre } \\
\text { para abajo. Los migrantes que vengan, que refaccionen sus casas, que } \\
\text { hagan un hotel. }\end{array}$ \\
\hline Restauración & $\begin{array}{l}\text { GV: Hay un déficit de restaurantes que brinden servicios de calidad, Falta } \\
\text { modernizar los comedores, los restaurantes. }\end{array}$ \\
\hline Transporte & $\begin{array}{l}\text { GV: En cuanto a servicio de transporte hay micros. } \\
\text { DV: Las empresas de transporte cobran tres o cuatro veces más que las que } \\
\text { van a Huaral, a Huacho. }\end{array}$ \\
\hline
\end{tabular}

\section{INFRAESTRUCTURA}

\begin{tabular}{|l|l|}
\hline INFRAESTRUCTURA & ENTREVISTADO \\
\hline Carreteras & $\begin{array}{l}\text { BR: Todos son destinos turísticos, depende de la infraestructura. Si los } \\
\text { gobiernos regionales hicieran esta carretera transversal que va de Canta, a } \\
\text { San José, Huamantanga, Quipán, Marco, Sumbilca, y llega hasta la zona } \\
\text { de Acos en Chancay, entonces se uniría Huaral con Canta y Lima, y por ahí } \\
\text { también, hacia la cima, se puede salir a La Viuda y a Junín. Por otro lado } \\
\text { se va por Huayllay y se conecta con la carretera Central. Cualquier pueblo } \\
\text { es un destino turístico. Se va a Carhua, se va a Marco, se va a Puruchuco, } \\
\text { todos son destinos turísticos. Entonces es una política de Estado pavimentar } \\
\text { esas carreteras. Se sube cuatro, cinco, seis pisos ecológicos. }\end{array}$ \\
$\begin{array}{ll}\text { GV: Falta la ruta Pariamarca, Carhua, Lachaqui y para eso se tiene que } \\
\text { hacer una buena carretera. Falta elaborar más ese circuito que vaya de } \\
\text { Canta, Pariamarca, Carhua, Lachaqui, baje a Arahuay, Collo, Licahuasi } \\
\text { hasta Santa Rosa de Quives. Por otro lado, falta desarrollar el otro circuito } \\
\text { que va por San José, Huamantanga, Quipán, Marco, Sumbilca, Huandaro, } \\
\text { La Perla y de ahí a Huaral. Y los macrocircuitos, pero requieren una } \\
\text { carretera muy buena, hasta Cerro de Pasco. }\end{array}$ \\
\hline $\begin{array}{l}\text { MH: Darle valor pedagógico a Checta, que haya lecturas, guías. Ni siquiera } \\
\text { está delimitado, no hay itinerario, no hay flechas, no hay absolutamente nada. } \\
\text { En Santa Rosa de Quives, la gente va a padecer, acuden grupos enormes. } \\
\text { Debe establecerse todo un sistema de comunicación indispensable. }\end{array}$ \\
\hline \multirow{2}{*}{ Información y asistencia al turista }
\end{tabular}




\section{IMPORTANCIA DEL TURISMO}

MH: Creo que el turismo es ahora una gran oportunidad, un factor de desarrollo que puede sacar a Canta de la marginación, del abandono en que vive. Poner en valor todos los recursos que tiene para mostrar a los visitantes lo valioso de nuestra tradición, de los restos arqueológicos que tiene nuestra tierra, y el paisaje básicamente.

GV: El turismo es ya un verdadero factor del desarrollo, que falta encaminarlo, impulsarlo más.

BR: Yo pienso que es esencial. Tiene muchas cosas buenas, son ventajas comparativas, que casi no tienen otros pueblos, otras provincias, como su cercanía a Lima.

DV: Es prioridad uno. Genera trabajo y de repente revierte la migración porque ya menos pobladores se van a ir a Lima.

\section{CONCLUSIONES}

El presente estudio contribuye al conocimiento del gran potencial turístico que existe en la provincia de Canta. El resultado de las entrevistas resalta la cantidad de atractivos turísticos que posee: paisajes, pisos ecológicos, condiciones climáticas, arqueología, folclore, gastronomía, fiestas patronales, entre otros.

Los entrevistados coinciden en la necesidad de mejorar los servicios turísticos, mencionan que no hay suficientes establecimientos de hospedaje ni restaurantes, y los que existen deben ser modernizados y mejorar su atención.

Estos resultados también sugieren una mayor participación de los gobiernos locales, en coordinación con el gobierno regional, en el desarrollo de infraestructura vial, energética, de comunicaciones, de servicios básicos, así como también en acceso a la información y asistencia a los turistas.

Todos los entrevistados concuerdan en que el turismo es muy importante y un factor de desarrollo para Canta. Como medida prioritaria proponen la necesidad de valorizar sus recursos y aprovechar su cercanía a Lima.
En consecuencia, se reconoce la potencialidad de esta provincia como destino turístico sostenible. Para ello es necesario invertir en infraestructura adecuada para atraer al visitante. Todo esto se logrará con el trabajo conjunto del sector público y del sector privado, y con la participación de las comunidades.

Finalmente se puede afirmar que Canta cuenta con numerosos atractivos destacables. Posee la enorme ventaja de la cercanía a Lima, pero necesita inversión en estructura vial, hotelera y de servicios turísticos que la puedan convertir en un destino competitivo a nivel nacional.

\section{Bibliografía}

Acerenza, Miguel

2008 Gestión municipal del turismo. México: Trillas.

Ascensión, Félix

2005 Turismo sostenible en el Perú: planificación, gestión y desarrollo. Lima: Editorial Universitaria.

Barretto, Margarita

2007 Turismo y cultura: relaciones, contradicciones y expectativas. El Sauzal, Tenerife.

Bazán, Carlos, Miriam Gayoso, Pedro Mendoza y Jorge Moreno

2007 Manual CTN de buenas prácticas para un turismo sostenible y calidad de los servicios. Lima: Concytec.

Couillaud, Dennis

2006 Marketing turístico y hotelero. Lima: Universidad de San Martín de Porres.

Fernández de Tejada, A. y A. Iniesta

1999 "Caracterización de la oferta y demanda en ecoturismo". En: Turismo en espacios naturales. Valencia: Universidad Politécnica de Valencia, pp. 59-79.

Guerra, Carlos 2002 "La planificación como instrumento para el desarrollo turístico sostenible de los atractivos naturales y culturales". En: Turismo y desarrollo sostenible. Daniel Meyer, encargado de la investigación. Bogotá: Universidad Externado de Colombia, pp. 87-101. 
Hernández, Roberto, Carlos Fernández y Pilar Baptista

2003 Metodología de la investigación. México: Mc Graw-Hill.

Leiva, Víctor

1997 "Turismo y gestión municipal". Manual $N^{\circ}$ 9. Serie de manuales didácticos para la gestión municipal de la Asociación Chilena de Municipalidades, Santiago.

Meyer, Daniel

2002 Turismo y desarrollo sostenible. Bogotá: Universidad Externado de Colombia.

Morán, María Ángeles

2001 "Medio ambiente y desarrollo sostenible en las regiones económicas de Mercosur y Unión Europea". En: Espacio y Desarrollo No 13. Lima: Fondo Editorial de la Pontificia Universidad Católica del Perú.
Pantano, Eduardo 2002 "La planificación como instrumento para el desarrollo turístico sostenible de los atractivos naturales y culturales". En: Turismo y desarrollo sostenible. Daniel Meyer, encargado de la investigación. Bogotá: Universidad Externado de Colombia.

Pérez, Mónica

2004 Manual de turismo sostenible. España: Ediciones Mundi-Prensa.

Torres, Martín

2005 "Principios del turismo equilibrado: conservación y desarrollo". En: Turismo sostenible: un enfoque multidisciplinar e internacional. Tomás López Guzmán y Fernando Lara de Vicente, coordinadores. Córdoba: Universidad de Córdoba. 